\title{
Trocas gasosas e fluorescência da clorofila a em variedades de cana-de-açúcar submetidas à deficiência hídrica ${ }^{1}$
}

\author{
Eduardo R. G onçalves ${ }^{2}$, Vilma M. Ferreira ${ }^{3}$, José V. Silva ${ }^{3}$, Laurício Endres ${ }^{3}$, Tadeu P. Barbosa ${ }^{4} \&$ Weverton de G. Duarte ${ }^{4}$
}

RESUMO

O estresse hídrico afeta grande parte da agricultura mundial, razão por que se propôs, através deste trabalho, avaliar o comportamento, em casa-de-vegetação, de quatro variedades de cana-de-açúcar (SP79-1011, RB72454, RB98710 e RB92579) submetidas a déficit hídrico durante a fase inicial de crescimento vegetativo. As plantas foram cultivadas em vasos plásticos contendo $15 \mathrm{~kg}$ de solo. O estudo foi um fatorial (4 variedades x 3 níveis de água disponível no solo), em delineamento inteiramente casualizado, com cinco repetições. Os níveis de água no solo foram baseados na capacidade de água disponível (CAD) ficando assim definidos: controle (80 a 100\% da CAD), estresse hídrico moderado ( 40 a 60\% da CAD) e estresse hídrico severo ( 0 a $20 \%$ da CAD). A deficiência hídrica provocou reduções significativas na condutância estomática (gs), transpiração foliar (E), fotosíntese líquida (A) e na eficiênca de uso da água de produção $\left(\mathrm{EUA}_{\mathrm{p}}\right)$, independente da variedade. As variedades SP79-1011 e RB98710 apresentaram maior sensibilidade estomática, reduzindo $\mathrm{g}_{\mathrm{s}} \mathrm{e} E$ aos 71 dias após início do estresse, mesmo sob condições controle; entretanto, em tais condições A foi pouco afetada, indicando que as plantas são capazes de manter a taxa fotossintética, mesmo com os estômatos parcialmente fechados. O estresse hídrico provocou pouca redução na eficiência fotoquímica potencial das variedades estudadas.

Palavras-chave: fotossíntese, condutância estomática, estresse hídrico

\section{Gas exchange and chlorophyll a fluorescence of sugarcane varieties submitted to water stress}

\begin{abstract}
Water stress affects a great part of the world's agriculture. Thus, this work was conducted to evaluate photosynthetic traits in four varieties of sugarcane (SP79-1011, RB72454, RB98710 and RB92579) submitted to water stress during the early stage of the vegetative period. The plants were cultivated in plastic pots ( $15 \mathrm{~kg}$ of soil). The study was a factorial ( 4 varieties $\mathrm{x} 3$ levels of soil water content based on available water capacity (AWC)), in a completely randomized design with 5 replications. The levels of water content in the soil were as follows: control ( 80 to $100 \%$ of AWC), moderate water stress ( 40 to $60 \%$ of AWC) and severe water stress ( 0 to $20 \%$ of AWC). Water stress provoked a significant reduction in stomatic condutance (g), foliar transpiration (E), net photosynthesis (A) and in the water use efficiency of production (WUE $)_{y}$, irrespective of varieties. The varieties SP79-1011 and RB98710 showed greater stomatal sensitivity, reducing $\mathrm{g}_{\mathrm{s}}$ and $\mathrm{E}$ by the 71 days after the beginning of the water stress treatments, even in the control. However, under such conditions A was little affected, indicating that the plants are capable to fixing $\mathrm{CO}_{2}$ with stomata partially closed. Water stress caused a small reduction in the potential photochemical efficiency $\left(F_{v} / F_{m}\right.$ ratio $)$ in the studied varieties.
\end{abstract}

Key words: photosinthesys, stomatal conductance, water stress

1 Parte da dissertação de mestrado do primeiro autor, apresentada à Universidade Federal de Alagoas

${ }^{2}$ Mestrando em Agronomia/Produção Vegetal/UFAL, Campus Delza Gitai. BR 104 Norte, km 85. CEP 57100-000, Rio Largo, AL. Fone (82) 3261-1956. E-mail: eduregon@yahoo.com.br

3 UFAL. Fone (82) 3261-1956. E-mail:vmarques_ferreira@hotmail.com; jovisi@yahoo.com.br; lauricioendres@hotmail.com

${ }^{4}$ Graduandos de Agronomia CECA/UFAL, bolsistas CNPq/PIBIC. Fone (82) 3261-1956. E-mail: tadeupbarbosa@gmail.com; vetowg@hotmail.com 


\section{INTRODUÇÃO}

A deficiência hídrica dos solos é um problema que afeta boa parte das áreas cultivadas no mundo, principalmente as situadas em regiões semiáridas, reduzindo o crescimento e a produção vegetal, provocando prejuízos socioeconômicos (Munns, 2002). No Brasil, este impasse é percebido, sobretudo na região Nordeste, na qual aproximadamente $54 \%$ de toda a área se situam no semiárido (FAO, 2008), abrangendo áreas cultivadas, irrigadas ou não. Sabe-se que existe grande variabilidade intra e interespecífica, no que tange à adaptabilidade das espécies à seca; assim, torna-se importante avaliar o comportamento fisiológico de diferentes materiais genéticos frente ao déficit hídrico, de modo a permitir uma posterior recomendação de cultivo (Ribeiro et al., 2004).

A cana-de-açúcar, espécie moderadamente sensível ao estresse hídrico (Maas \& Hoffman, 1977), encontra-se distribuída, no Brasil, em uma área superior a 7,1 milhões de hectares, com estimativa de produção, para 2008, de aproximadamente 550 milhões de toneladas. Em contrapartida, a região Nordeste apresenta, de maneira geral, produtividade baixa, apesar do aumento observado nos últimos anos em razão do uso de variedades selecionadas e melhoradas (IBGE, 2008).

Diversos são os trabalhos que mostram a influência da deficiência hídrica nas trocas gasosas sobre as culturas, em especial sobre a cana-de-açúcar (Arias et al., 1996; Inman-Bamber \& Smith, 2005; Smit \& Singels, 2006), milho (Bergonci \& Pereira, 2002; Cruz, 2006), sorgo (Nable et al., 1999) e outras gramíneas $\mathrm{C}_{4}$ (Ghannoum et al., 2003); desta forma, em condições de estresse hídrico as variáveis de trocas gasosas podem apresentar alterações de forma distinta, de acordo com a espécie, tanto por limitações difusivas, restringindo a disponibilidade de dióxido de carbono para assimilação, quanto por limitações metabólicas, pelo aumento do efeito fotoinibitório (Glaz et al., 2004); neste sentido, a técnica do rendimento quântico do fotossistema II (PSII), obtido a partir da fluorescência da clorofila a, pode revelar o nível energético de excitação dos pigmentos que dirigem a fotossíntese; então, a habilidade em manter elevadas razões $F_{v} / F_{m}$ sob estresse hídrico pode ser um indicativo de eficiência no uso da radiação pela fotoquímica e, consequentemente, a assimilação de carbono (Tester \& Bacic, 2005), assim como uma resposta relativamente rápida de $\mathrm{F}_{\mathrm{v}} / \mathrm{F}_{\mathrm{m}}$ ao estresse hídrico moderado pode ser um traço importante na seleção de variedades de canade-açúcar (Silva et al., 2007), milho (Cruz, 2006) e gramíneas $\mathrm{C}_{4}$ (Ghannoum et al., 2003) tolerantes a seca; desta maneira, as medidas de trocas gasosas e de fluorescência da clorofila a podem ser utilizadas como ferramentas para diagnosticar a integridade do aparato fotossintético frente às adversidades ambientais, tendo em vista que se trata de técnicas rápidas, precisas e não destrutivas (Torres Netto et al., 2005), de modo a contribuir significativamente com outras áreas do conhecimento (e.g. melhoramento genético e biotecnologias associadas).

Diante dos relatos supracitados, o presente trabalho teve por finalidade avaliar, de forma comparativa, variáveis relacionadas às trocas gasosas de quatro variedades de cana-de- açúcar quando submetidas a déficit hídrico durante a fase inicial de crescimento vegetativo, visando identificar características morfofisiológicas e bioquímicas para auxiliar o programa de melhoramento genético da cultura no processo de cruzamento e seleção de novas variedades.

\section{MATERIAL E MÉTODOS}

O experimento foi conduzido em casa-de-vegetação do setor de Fisiologia Vegetal da Unidade Acadêmica Centro de Ciências Agrárias, Campus Delza Gitaí, da Universidade Federal de Alagoas, localizada no município de Rio Largo $\left(09^{\circ}\right.$ $28^{\prime}$ S, $35^{\circ} 49^{\prime}$ W e $127 \mathrm{~m}$ de altitude), Estado de Alagoas. Utilizaram-se quatro variedades de cana-de-açúcar (Saccharum spp.) escolhidas com base nas informações obtidas junto ao programa de melhoramento genético da cultura (PMGCA/CECA/UFAL). Visando ao estudo de variedades tolerantes e suscetíveis ao estresse hídrico, escolheram-se as variedades RB92579 e SP79-1011 e as variedades RB98710 e RB72454, consideradas tolerantes e suscetíveis, respectivamente; ademais, tais variedades foram assim escolhidas em virtude da sua grande utilização no Estado de Alagoas.

Os vasos foram preparados seguindo-se recomendações contidas em Beltrão et al. (2002) de modo a aumentar a reflectância e reduzir o aquecimento do substrato. Para garantir o enraizamento e uma homogeneidade maior das plântulas, os rebolos com uma única gema de cana-de-açúcar foram plantados previamente em um canteiro localizado em um galpão coberto; decorridos dezessete dias do plantio (DAP), duas plântulas foram transferidas para os vasos plásticos $(30 \mathrm{~cm}$ de altura e $30 \mathrm{~cm}$ de diâmetro), cada qual contendo $15 \mathrm{~kg}$ de solo destorroado, peneirado e homogeneizado. Os vasos foram pesados diariamente mantendo-se a umidade do solo próximo à capacidade de campo (CC) até a aplicação dos tratamentos, aos 70 DAP; a partir de então, os mesmos foram pesados e sua massa corrigida de acordo com a água disponível do solo (AD), previamente estabelecida com base em sua análise gravimétrica. Através da curva de retenção de umidade do solo obtiveram-se o ponto de murcha permanente $(-1,5 \mathrm{MPa})$ e a capacidade de campo $(-0,03 \mathrm{MPa})$ de $10,5 \mathrm{e}$ $18 \%$ da massa seca do solo, respectivamente; assim, os tratamentos foram denominados da seguinte forma: controle ( 80 a $100 \% \mathrm{AD}$ ), estresse moderado (40 a $60 \% \mathrm{AD}$ ) e estresse severo (0 a $20 \% \mathrm{AD})$.

Durante o período experimental as condições ambientais no interior da casa-de-vegetação, representadas pela temperatura média e umidade relativa média do ar, medidas diariamente com termohigrógrafo, foram $29,2 \pm 2,9{ }^{\circ} \mathrm{C}$ e $63,4+5,6$ $\%$, respectivamente, enquanto as avaliações das trocas gasosas se iniciaram aos $70 \mathrm{DAP}$, tal como os tratamentos, repetindo-se 16 dias depois (86 DAP), passando a serem avaliadas semanalmente a partir desta data; as avaliações foram realizadas sempre na porção mediana da folha +2 (segunda folha mais jovem completamente expandida) da mesma planta, até os 141 DAP, obtendo-se os valores de fotossíntese líquida $(A)$, condutância estomática $\left(\mathrm{g}_{\mathrm{s}}\right)$ e transpiração $(\mathrm{E})$, utilizando-se de um analisador de gás a infravermelho IRGA 
(ADC, modelo LCi, Hoddesdon, UK), com fluxo de ar de 300 $\mathrm{mL} \mathrm{m^{-1 }}$ e fonte de luz acoplada de $995 \mathrm{mmol} \mathrm{m}^{-2} \mathrm{~s}^{-1}$. As medições ocorreram entre 8 e $11 \mathrm{~h}$, utilizando-se umidade relativa e temperatura do ar do ambiente (Figura 1). De posse dos dados obtidos de trocas gasosas $\left(\mathrm{g}_{\mathrm{s}}, \mathrm{A}\right.$ e $\left.\mathrm{E}\right)$, calculou-se o percentual de redução, entre a primeira, 0 dias após início do estresse hídrico (DAE), quando as plantas estavam sob as mesmas condições hídricas e a última leitura (71 DAE), dia anterior ao da coleta final do experimento. A eficiência no uso da água da produtividade $\left(\mathrm{EUA}_{\mathrm{p}}\right)$ foi calculada pela relação entre matéria seca produzida e o total de água evapotranspirada ao longo do experimento (Larcher, 2004).

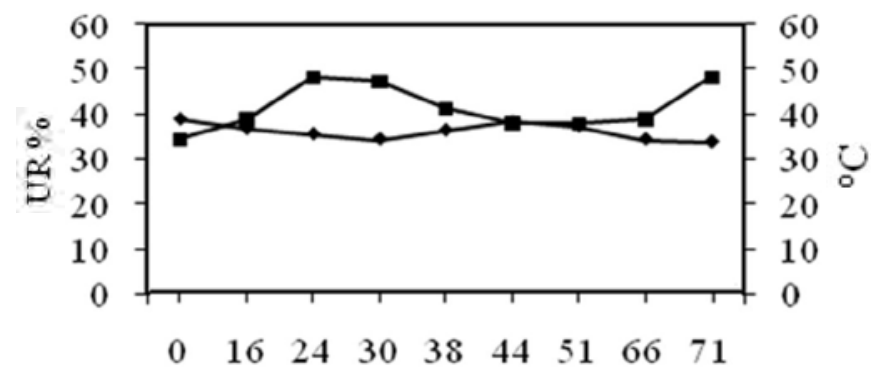

Dias apósinicio do estresse hídrico

Figura 1. Temperatura (-๑) e umidade relativa do ar (- - $)$ no interior da casade-vegetação durante as medições de trocas gasosas e de fluorescência do fotossistema II em quatro variedades de cana-de-açúcar sob estresse hídrico

A emissão de fluorescência da clorofila a foi quantificada com a utilização de fluorômetro portátil de luz modulada (OptiSciences, modelo OS1-FL, Hudson, USA), a partir do qual se obtiveram a fluorescência inicial $\left(\mathrm{F}_{0}\right)$, a fluorescência máxima $\left(F_{m}\right)$, a fluorescência variável $\left(F_{v}\right)$ e o rendimento quântico máximo do PSII $\left(\mathrm{F}_{\mathrm{v}} / \mathrm{F}_{\mathrm{m}}\right)$, após adaptação das folhas ao escuro (H'30 min). As medições ocorreram nas mesmas épocas daquelas de trocas gasosas, porém em horário distinto, sempre entre 11 e $13 \mathrm{~h}$; tal horário foi escolhido pelo fato de ser o mais crítico na região, no tocante à temperatura e incidência da radiação solar no qual ocorre, provavelmente, maior dano ao aparato fotossintético refletindo, portanto, o status do aparato fotossintético instantâneo. Duas leituras foram realizadas em cada planta, sempre na porção mediana da folha +2 .

$\mathrm{O}$ experimento foi disposto em delineamento inteiramente ao acaso com arranjo fatorial 4 (variedades) x 3 (níveis de estresse) com 5 repetições. A parcela foi constituída de um vaso contendo duas plantas. Os dados foram submetidos a análise de variância e as médias comparadas pelo teste Tukey, com $\mathrm{P} \leq 0,05$ (Ferreira, 2000).

\section{RESULTADOS E DISCUSSÃO}

De maneira geral, verificou-se redução nas variáveis de trocas gasosas [condutância estomática $\left(\mathrm{g}_{\mathrm{s}}\right)$, transpiração $(\mathrm{E})$ e fotossíntese $(\mathrm{A})]$, assim como na eficiência do uso da água na produtividade $\left(\mathrm{EUA}_{\mathrm{p}}\right)$ ao longo do período experimental (Figuras 2, 3 e 4; Tabela 1), e entre as avaliações realizadas no início do estresse hídrico (0 DAE) e no dia anterior ao da

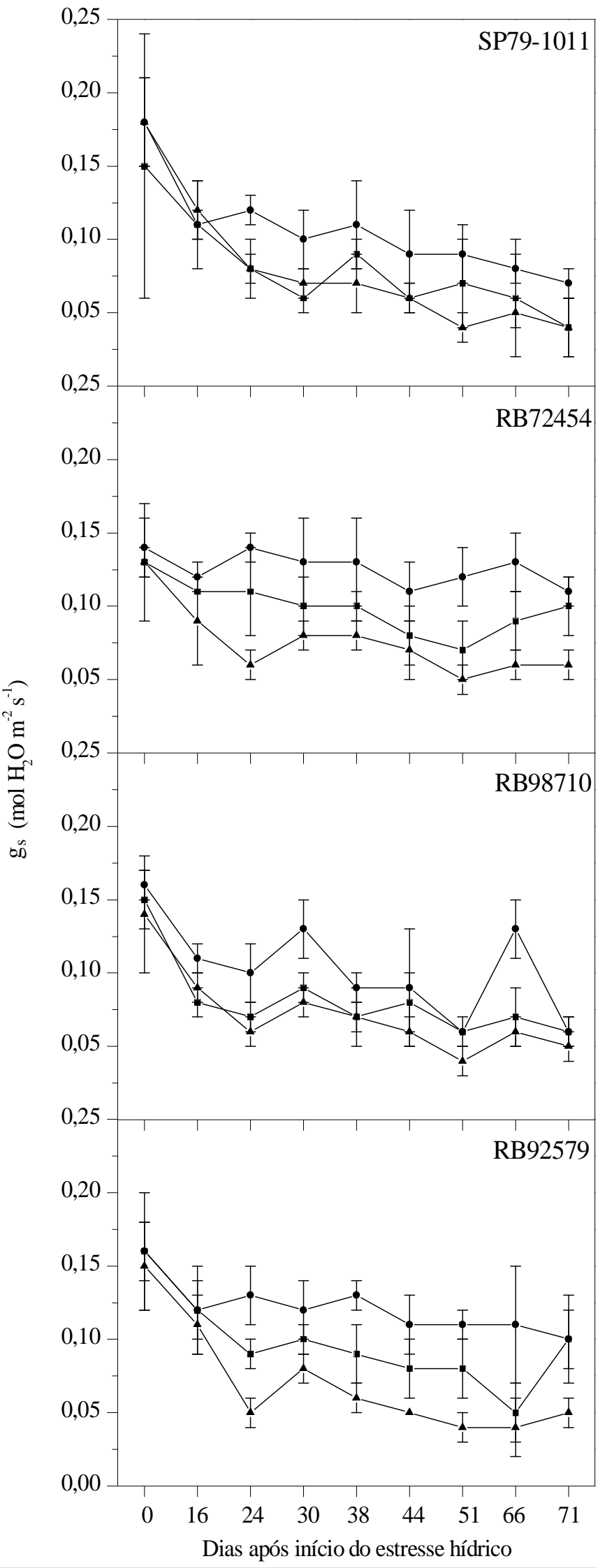

Figura 2. Condutância estomática (g ) em folhas de quatro variedades de cana-

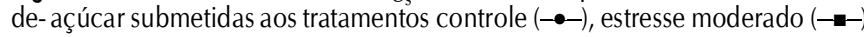
e estresse severo (- - ), cultivadas em casa-de-vegetação em função dos dias de exposição ao déficit hídrico. As barras indicam o desvio padrão da média de quatro observações 


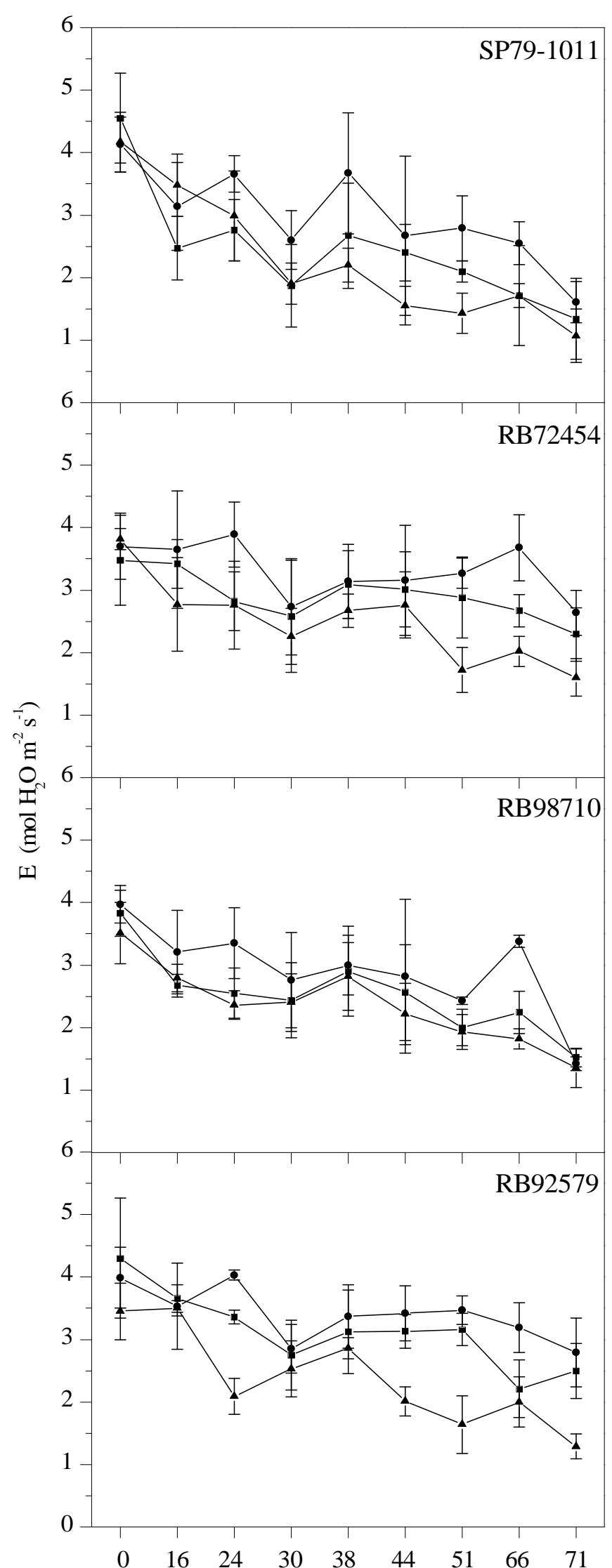

Dias após início do estresse hídrico

Figura 3. Transpiração foliar (E) de quatro variedades de cana-de-açúcar submetidas aos tratamentos controle $(-\bullet)$, estresse moderado $(--)$ e estresse severo (- c) cultivadas em casa-de-vegetação em função dos dias de exposição ao déficit hídrico. As barras indicam o desvio padrão da média de quatro observações

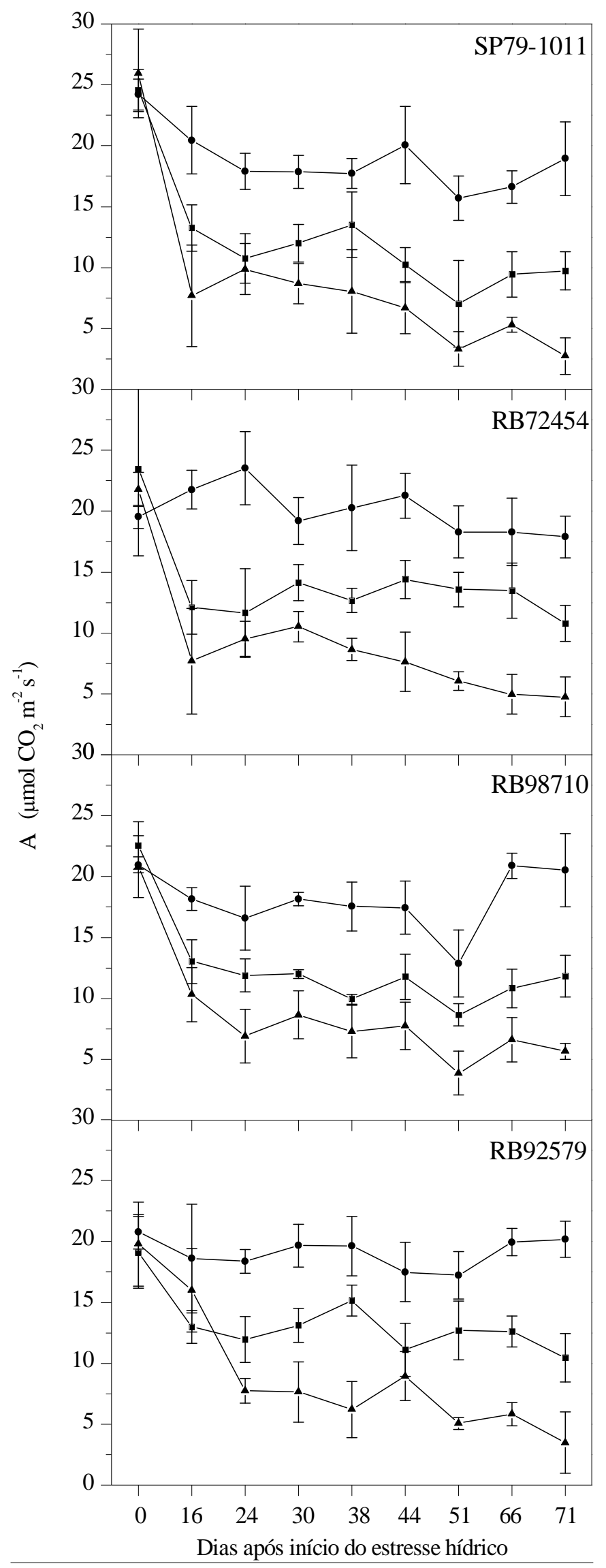

Figura 4. Fotossíntese líquida ( $\mathrm{A}$ ) em folhas de quatro variedades de cana-de-açúcar submetidas aos tratamentos controle $(-\bullet)$, estresse moderado (- - e estresse severo ( - - ) cultivadas em casa-de-vegetação em função dos dias de exposição ao déficit hídrico. As barras indicam o desvio padrão da média de quatro observações 
Tabela 1. Variações nas variáveis de trocas gasosas [condutância estomática $\left(g_{s}\right)$, transpiração foliar (E) e fotossíntese líquida $\left.(A)\right]$ entre 0 e 71 dias após a aplicação do estresse e eficiência no uso da água da produtividade (EUA $\mathrm{p}_{\mathrm{p}}$ ) em quatro variedades de canade-açúcar submetidas aos tratamentos controle (80 a 100\% AD), estresse moderado (40 a $60 \%$ AD) e estresse severo ( 0 a $20 \%$ AD) cultivadas em casa-de-vegetação aos 141 dias após o plantio

\begin{tabular}{|c|c|c|c|c|c|}
\hline \multirow{2}{*}{\multicolumn{2}{|c|}{ Variedades Trat* }} & \multicolumn{4}{|c|}{ Trocas Gasosas } \\
\hline & & $\begin{array}{c}\text { gs** } \\
\text { Redução(\%) }\end{array}$ & $\begin{array}{c}\text { E** } \\
\text { Redução(\%) }\end{array}$ & $\begin{array}{c}\text { A** Redução/ } \\
\text { Aumento(\%) }\end{array}$ & $\begin{array}{c}\text { EUAp } \\
\mathrm{gMS} / \mathrm{kgH}_{2} \mathrm{O}\end{array}$ \\
\hline \multicolumn{6}{|c|}{ Variedade x Estresse Hídrico } \\
\hline & C & $64,76 \mathrm{Aa}$ & $49,29 \mathrm{ABb}$ & $20,79 \mathrm{Ac}$ & 4,77 Аa \\
\hline \multirow[t]{3}{*}{ SP79-1011 } & $E M$ & $65,82 \mathrm{Aa}$ & $58,57 \mathrm{Aab}$ & $56,36 \mathrm{Ab}$ & $3,56 \mathrm{Ab}$ \\
\hline & ES & $74,59 \mathrm{Aa}$ & $71,59 \mathrm{Aa}$ & $88,83 \mathrm{Aa}$ & $2,68 \mathrm{Ac}$ \\
\hline & C & $25,96 \mathrm{Bb}$ & $34,33 \mathrm{Bb}$ & $+0,78 \mathrm{Ab}$ & 4,57 Аa \\
\hline \multirow[t]{3}{*}{ RB72454 } & $E M$ & $35,25 \mathrm{Ab}$ & $52,20 \mathrm{Aab}$ & $48,45 \mathrm{Aa}$ & $3,63 \mathrm{Ab}$ \\
\hline & ES & $69,52 \mathrm{Aa}$ & $58,58 \mathrm{Aa}$ & $71,84 \mathrm{Aa}$ & $2,73 \mathrm{AC}$ \\
\hline & C & $64,75 \mathrm{Aa}$ & $64,16 \mathrm{Aa}$ & $18,20 \mathrm{Ac}$ & $4,72 \mathrm{Aa}$ \\
\hline \multirow[t]{3}{*}{ RB98710 } & $E M$ & $53,33 \mathrm{Aa}$ & $59,78 \mathrm{Aa}$ & $43,83 \mathrm{Ab}$ & $3,80 \mathrm{Ab}$ \\
\hline & ES & $68,37 \mathrm{Aa}$ & $68,57 \mathrm{Aa}$ & $70,52 \mathrm{Aa}$ & $2,68 \mathrm{Ac}$ \\
\hline & C & $38,41 \mathrm{ABa}$ & $44,33 \mathrm{ABb}$ & $13,28 \mathrm{AC}$ & $4,64 \mathrm{Aa}$ \\
\hline \multirow[t]{2}{*}{ RB92579 } & $E M$ & $53,02 \mathrm{Aa}$ & $57,50 \mathrm{Aab}$ & $49,48 \mathrm{Ab}$ & $3,47 \mathrm{Ab}$ \\
\hline & ES & $60,09 \mathrm{Aa}$ & $69,04 \mathrm{Aa}$ & $81,17 \mathrm{Aa}$ & $2,95 \mathrm{Ac}$ \\
\hline \multicolumn{6}{|l|}{ Tratamento } \\
\hline & C & $48,47 b$ & $48,03 \mathrm{~b}$ & $12,87 \mathrm{c}$ & $4,68 \mathrm{a}$ \\
\hline & $\mathrm{EM}$ & $51,85 b$ & $57,01 \mathrm{~b}$ & $49,53 \mathrm{~b}$ & $3,62 b$ \\
\hline & ES & $68,14 \mathrm{a}$ & $66,94 \mathrm{a}$ & $78,34 \mathrm{a}$ & $2,76 \mathrm{c}$ \\
\hline CV (\%) & & 32,01 & 19,19 & 29,11 & 5,77 \\
\hline
\end{tabular}

*Tratamentos: $\mathrm{C}=$ controle; $\mathrm{EM}=$ estresse moderado; $\mathrm{ES}=$ estresse severo; **Redução ou aumento (+), em \%, entre a primeira (imposição dos tratamentos) e a última leitura aos 71 dias; ***Médias seguidas de letras iguais na mesma coluna, tanto para tratamentos dentro da variedade (letras minúsculas), como para variedades dentro de tratamento (letras maiúsculas), não diferem estatisticamente entre si a nível de $5 \%$ de probabilidade pelo teste de Tukey

coleta, aos 71 DAE (Tabela 1), mas as reduções mais acentuadas ocorreram nas plantas submetidas ao tratamento de estresse hídrico severo (Tabela 1). Com base, ainda, na mesma tabela, observa-se que as plantas submetidas ao tratamento controle, ou seja, sem restrição hídrica, apresentaram decréscimo nos valores das variáveis de trocas gasosas, indicando uma possível limitação do tamanho do vaso, tendo em vista que na fase final do experimento as plantas se encontravam mais desenvolvidas vegetativamente e então exauriam água do solo mais rápido proporcionando, talvez, a ocorrência de certa limitação hídrica em algumas horas do dia, embora tenham sido pesadas diariamente para correção da umidade perdida através da evapotranspiração.

Ao se analisar o efeito do déficit hídrico dentro das variedades verificou-se que, com a restrição da água disponível no solo, ocorreu redução em $\mathrm{g}_{\mathrm{s}}$ nos quatro genótipos, porém a variedade RB72454 foi a única que apresentou reduções significativas entre os tratamentos, sobretudo entre o controle e o estresse severo (Tabela 1). Esses resultados mostram que, sob estresse severo, uma das primeiras respostas da RB72454 pode ser o fechamento estomático, de forma a minimizar a perda de água (Larcher, 2004; Taiz \& Zeiger, 2004). Por outro lado, as plantas das variedades SP79-1011, RB98710 e RB92579 apresentaram reduções significativas na condutância estomática, entre o início e o final do experimento, mostrando que as plantas do tratamento controle sofreram restrição hídrica ao final do experimento e essas variedades responderam prontamente com redução da condutância estomática e transpiração (Tabela 1).

Esses resultados corroboram com os relatados por Smit \& Singels (2006) que notaram reduções na condutância estomática em duas variedades de cana-de-açúcar, afirmando que tal variável apresenta maior sensibilidade que o potencial hídrico a medida em que o solo se torna mais seco. Bergonci \& Pereira (2002) apesar de também encontrarem redução em $g_{s}$ em milho, afirmam que o potencial hídrico foliar diminui mais rapidamente frente à fração de água disponível no solo para as plantas; outro aspecto que merece ressalva, é o fato de que, sob condições controle, as variedades RB72454 e RB92579 mostraram menores reduções percentuais nas taxas de abertura dos estômatos $(25,96$ e 38,41\%, respectivamente), enquanto as variedades SP79-1011 e RB98710 indicaram reduções mais elevadas na condutância estomática (64,76 e $64,75 \%$, respectivamente) (Tabela 1). Este comportamento das variedades também é verificado na Figura 4, na qual se tem a condutância estomática em função dos dias após o início do estresse hídrico e nela também se constatou que apesar de ocorrer tendência de redução na $\mathrm{g}_{\mathrm{s}}$ ao longo do tempo, não houve, de maneira geral, diferença entre os quatro genótipos quanto à resposta aos tratamentos aplicados.

Ao se analisar as reduções na transpiração foliar de forma isolada verificou-se, na Tabela 1 , que as variedades apresentaram respostas diferenciadas. A variedade RB98710 não foi influenciada pelos tratamentos aplicados no tocante à transpiração foliar, semelhante ao que ocorreu com $\mathrm{g}_{\mathrm{s}}$; por outro lado, as variedades SP79-1011, RB72454 e RB92579 indicaram reduções mais pronunciadas, sobretudo quando submetidas a estresse hídrico severo. Reduções significativas na transpiração foliar também foram observadas em genótipos de milho (Cruz, 2006), assim como em variedades de cana-deaçúcar (Arias et al., 1996) submetidas a deficiência hídrica.

Nable et al. (1999) também encontraram reduções nas taxas transpiratórias em sorgo e cana-de-açúcar, sendo que nesta última foram mais severas, sempre que a fração de água disponível no solo decrescia. Bergonci \& Pereira (2002), observaram que a transpiração relativa em plantas de milho diminui com a restrição hídrica do solo tornando-se praticamente nula com $20 \%$ de água disponível no solo. Arias et al. (1996) relataram, ainda, que a resposta da intensidade transpiratória em cana-de-açúcar foi diretamente relacionada com a disponibilidade hídrica, sobretudo a partir dos três meses de plantio havendo, porém, redução na transpiração por unidade de superfície, de acordo com a idade da planta. Essas reduções podem sofrer influência de outros fatores, tais como a reduzida área foliar em decorrência do estresse hídrico e a camada limítrofe que envolve as folhas.

A tendência de redução nas taxas transpiratórias em todas as variedades coincidiu com as reduções observadas na condutância estomática ao longo do período experimental não havendo, porém, diferença entre as variedades (Figuras 2 e 3). Esta relação direta entre transpiração e condutância esto- 
mática é esperada, tendo em vista a diminuição do fluxo de vapor d'água para a atmosfera e, consequentemente, da transpiração, à medida em que se fecham os estômatos.

Verificou-se, mesmo sem limitação hídrica, que a transpiração apresentou redução suave ao longo do período experimental (Figura 3), sendo a variedade RB72454 aquela com menor percentual de redução (34,33\%), tal como ocorreu com a condutância estomática na mesma variedade (Tabela 1), o que pode acontecer, haja vista que nos primeiros estádios de desenvolvimento as plantas são menores e apresentam número reduzido de folhas, havendo mais radiação incidente elevando, por conseguinte, a temperatura, impulsionando a maiores taxas transpiratórias como forma de resfriamento foliar e/ou pelo fato de que, ao final do experimento, as plantas do tratamento controle poderiam ter sido submetidas a déficit hídrico, mesmo que temporário, devido ao seu maior tamanho, como já discutido.

Notou-se, na Tabela 1, redução da taxa de fotossíntese líquida entre as épocas de avaliação, em função dos dias de exposição ao estresse hídrico. Nas plantas submetidas ao tratamento controle a redução foi de $12,87 \%$ enquanto nos tratamentos de estresse moderado e estresse severo foi de 49,53 e 78,34\%, respectivamente, demonstrando que a taxa de assimilação líquida de $\mathrm{CO}_{2}$ foi fortemente afetada pela deficiência hídrica.

Pode-se verificar que, de maneira geral, a taxa fotossintética apresentou redução significativa em todas as variedades submetidas ao estresse hídrico (Figura 4 e Tabela 1); visualiza-se, na Figura 4, redução suave na taxa fotossintética das plantas sob controle enquanto nos demais tratamentos se observou redução mais acentuada, em particular no estresse hídrico severo, em que as taxas de assimilação líquida de $\mathrm{CO}_{2}$ atingiram valores inferiores a $5 \mu \mathrm{mol} \mathrm{CO}_{2} \mathrm{~m}^{-2} \mathrm{~s}^{-1}$.

Observou-se ainda, na Figura 4, que em todas as variedades submetidas aos tratamentos de estresse hídrico houve declínio acentuado na fotossíntese líquida, desde o início da aplicação do estresse, porém em condições de estresse moderado as variedades apresentaram tendência em manter a A constante enquanto sob estresse hídrico severo essas reduções foram mais drásticas.

Os resultados obtidos neste trabalho corroboram com os observados por Ghannoum et al. (2003) que encontraram reduções progressivas e substanciais na fotossíntese em quatro gramíneas de metabolismo $\mathrm{C}_{4}$ submetidas a deficiência hídrica. Os autores mostraram, ainda, que a taxa fotossintética pode não ser mantida só em níveis menores de disponibilidade hídrica (próximo a 25\% AD) como, também, detectada em níveis mais elevados (60\% AD), indicando que as respostas da fotossíntese são dependentes da espécie; este declínio da atividade fotossintética em decorrência do déficit hídrico, se dá paralelamente à diminuição do volume celular e, portanto, conjuntamente com a redução na turgescência (Larcher, 2004).

Sob condições em que não houve limitação hídrica, a fotossíntese líquida permaneceu entre 19 e $24 \mu \mathrm{mol} \mathrm{CO} \mathrm{CO}^{-2} \mathrm{~s}^{-1}$ (Figura 4), valores semelhantes aos encontrados em milho, por Cruz (2006), sob a mesma disponibilidade hídrica do solo. Esses valores foram inferiores aos relatados por Larcher (2004), baseados em uma compilação de resultados de diversos autores, em que a fotossíntese líquida em gramíneas $\mathrm{C}_{4}$ variava de 30 a $60 \mu \mathrm{mol} \mathrm{CO} \mathrm{Cm}^{-2} \mathrm{~s}^{-1}$ chegando, em casos extremos, a $80 \mu \mathrm{mol} \mathrm{CO}_{2} \mathrm{~m}^{-2} \mathrm{~s}^{-1}$, desde que as plantas estivessem em condições favoráveis, tais como radiação suficiente para saturação do processo fotossintético, temperatura ótima e bom suprimento hídrico. Neste trabalho um dos fatores que podem ter resultado em taxas fotossintéticas relativamente baixas, como observado, deve ter sido a utilização da fonte de luz de $995 \mu \mathrm{mol} \mathrm{m} \mathrm{m}^{-2}$, valor inferior aos $1500 \mu \mathrm{mol} \mathrm{m} \mathrm{m}^{-2} \mathrm{~s}^{-1}$ relatado por Larcher (2004), a partir do qual ocorre saturação lumínica para algumas gramíneas de metabolismo $\mathrm{C}_{4}$

A inibição da fotossíntese induzida pelo estresse hídrico pode ser devida à limitação estomática, como verificado em quatro diferentes espécies de gramíneas, por Ghannoum et al. (2003), porém no presente trabalho se verificou que tanto $\mathrm{g}_{\mathrm{s}}$ como E nas plantas sem limitação hídrica apresentaram reduções superiores às observadas em $\mathrm{A}$ sob as mesmas condições, o mesmo não ocorrendo para as plantas submetidas aos tratamentos de estresse hídrico, em que as reduções nessas variáveis foram aproximadas (Tabela 1). Pode-se inferir, portanto, que as plantas do tratamento controle, embora com os estômatos parcialmente fechados, mostraram tendência em manter (RB72454) ou reduzir, em menor proporção (SP79-1011, RB98710 e RB92579) a taxa de fotossíntese líquida. A assimilação de $\mathrm{CO}_{2}$ depende não só do grau de abertura dos estômatos mas, também, do aumento da resistência a difusão de $\mathrm{CO}_{2}$ e da atividade enzimática (Heuer, 1997; InmanBamber \& Smith, 2005).

Tal como as variáveis de trocas gasosas, a eficiência no uso da água na produtividade $\left(\mathrm{EUA}_{\mathrm{p}}\right)$ apresentou reduções significativas entre os tratamentos de estresse hídrico aplicados (Tabela 1); verificou-se, ainda, que sob condições controle as variedades indicaram valores superiores a $4 \mathrm{~g} \mathrm{MS} / \mathrm{kg}$ $\mathrm{H}_{2} \mathrm{O}$, semelhantes aos relatados por Larcher (2004) em plantas de metabolismo $\mathrm{C}_{4}$, tal como a cana-de-açúcar.

Ao se analisar os tratamentos dentro das variedades, verificou-se que a variedade RB92579 apresentou a menor redução $(36,4 \%)$ na $\mathrm{EUA}_{\mathrm{p}}$, entre os tratamentos controle e estresse hídrico severo enquanto as variedades SP79-1011, RB72454 e RB98710 indicaram reduções superiores a 40\%, não havendo, porém, diferença significativa entre elas. Referidas

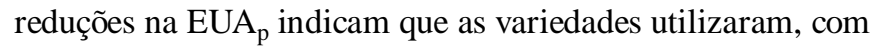
menos eficiência, a água, ou seja, produziram menor quantidade de matéria seca em virtude da baixa disponibilidade de água, fato também sustentado por Cruz (2006) que, em dois genótipos de milho, encontrou valores próximos a zero quando havia $50 \%$ de água disponível no solo, atribuindo a tais genótipos maior suscetibilidade ao déficit hídrico.

Arias et al. (1996) reforçam esta idéia afirmando que em cana-de-açúcar existe grande variabilidade na forma como as plantas usam a água, pois a relação assimilação de $\mathrm{CO}_{2} /$ consumo de água, pode ser afetada por fatores próprios da planta e do ambiente onde vivem. Larcher (2004) relata, em adição, que a melhor relação entre absorção de $\mathrm{CO}_{2}$ e consumo de $\mathrm{H}_{2} \mathrm{O}$ ocorre quando os estômatos estão parcialmente fechados, podendo ser demonstrada no início do estresse hídrico quando os dois processos de difusão são prontamente 
reduzidos, fazendo com que a $\mathrm{EUA}_{\mathrm{p}}$ alcance valores mais altos; verifica-se, então, que sob estresse hídrico severo a desidratação das células do mesofilo inibe fortemente o seu

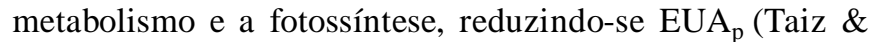
Zeiger, 2004).

A eficiência fotoquímica potencial das variedades em função dos dias após início do estresse hídrico é mostrada na Figura 5, na qual se verificou tendência de redução na relação $\mathrm{F}_{\mathrm{v}} / \mathrm{F}_{\mathrm{m}}$ sempre que o estresse hídrico se prolongava.

De maneira geral, a redução na água disponível do solo influenciou a eficiência fotoquímica potencial do fotossistema II (PSII), medida pela relação $\mathrm{F}_{\mathrm{v}} / \mathrm{F}_{\mathrm{m}}$, nas variedades de cana-de-açúcar, tanto ao longo do experimento (Figura 5), como entre as leituras observadas no início do estresse hídrico (0 DAE) e aos 71 DAE, último dia de medição (Tabela 2).

Analisando-se o efeito dos tratamentos dentro de cada variedade, verificaram-se respostas diferenciadas com tendência de aumento no percentual de redução da fluorescência da clorofila a nas variedades SP79-1011, RB72454 e RB98710, sobretudo se comparando os tratamentos controle e estresse hídrico severo (Tabela 2); por outro lado, na variedade RB92579 não se constatou alteração significativa entre os tratamentos, indicando que a maior parte da radiação talvez estivesse sendo utilizada na fase fotoquímica da fotossíntese não havendo, portanto, comprometimento do PSII em virtude do estresse hídrico; esta habilidade em manter valores semelhantes de $\mathrm{F}_{\mathrm{v}} / \mathrm{F}_{\mathrm{m}}$ sob estresse hídrico, pode indicar alta eficiência no uso da radiação possivelmente pelas reações de assimilação de carbono (Silva et al., 2007).

Observou-se ainda, em todos os tratamentos, que a variedade RB92579 apresentou os menores valores de $F_{v} / F_{m}$ durante o período experimental, o que pode explicar a não alteração observada na mesma variedade, podendo ser uma característica própria do genótipo. Bolhàr-Nordenkampf et al. (1989) relatam que, quando a planta está com seu aparelho fotossintético intacto, a razão $F_{\mathrm{v}} / \mathrm{F}_{\mathrm{m}}$ deve variar entre 0,75 e 0,85 enquanto uma queda nesta razão reflete a presença de dano fotoinibitório nos centros de reação do PSII. Os valores de $\mathrm{F}_{\mathrm{v}} / \mathrm{F}_{\mathrm{m}}$ observados nas variedades submetidas ao tratamento controle $(<0,8)$ (Figura 5), apesar de estarem dentro da amplitude citada anteriormente, diferem daqueles apresentados por Silva et al. (2007) que encontraram razões superiores a 0,8 em genótipos de cana-de-açúcar sob plena hidratação; tal fato pode ter ocorrido em razão de diversos fatores, dentre os quais o horário de avaliação e as condições climáticas no interior da casa-de-vegetação, sobremaneira as temperaturas elevadas observadas durante o momento de avaliação (Figura 1).

$\mathrm{Na}$ literatura se encontram resultados contraditórios na relação $\mathrm{F}_{\mathrm{v}} / \mathrm{F}_{\mathrm{m}}$ em resposta à redução na disponibilidade hídrica do solo. Lichtenthaler \& Miehé (1997) afirmam que, em geral, as plantas apresentam sintomas característicos em seu aparato fotossintético, tal como rápido decréscimo na relação $\mathrm{F}_{\mathrm{v}} / \mathrm{F}_{\mathrm{m}}$ sempre que o solo seca, como em milho (Cruz, 2006); por outro lado, Ghannoum et al. (2003) não encontraram alterações significativas na relação $F_{v} / F_{m}$ em quatro espécies de gramíneas de ciclo $\mathrm{C}_{4}$, indicando que a capacidade de

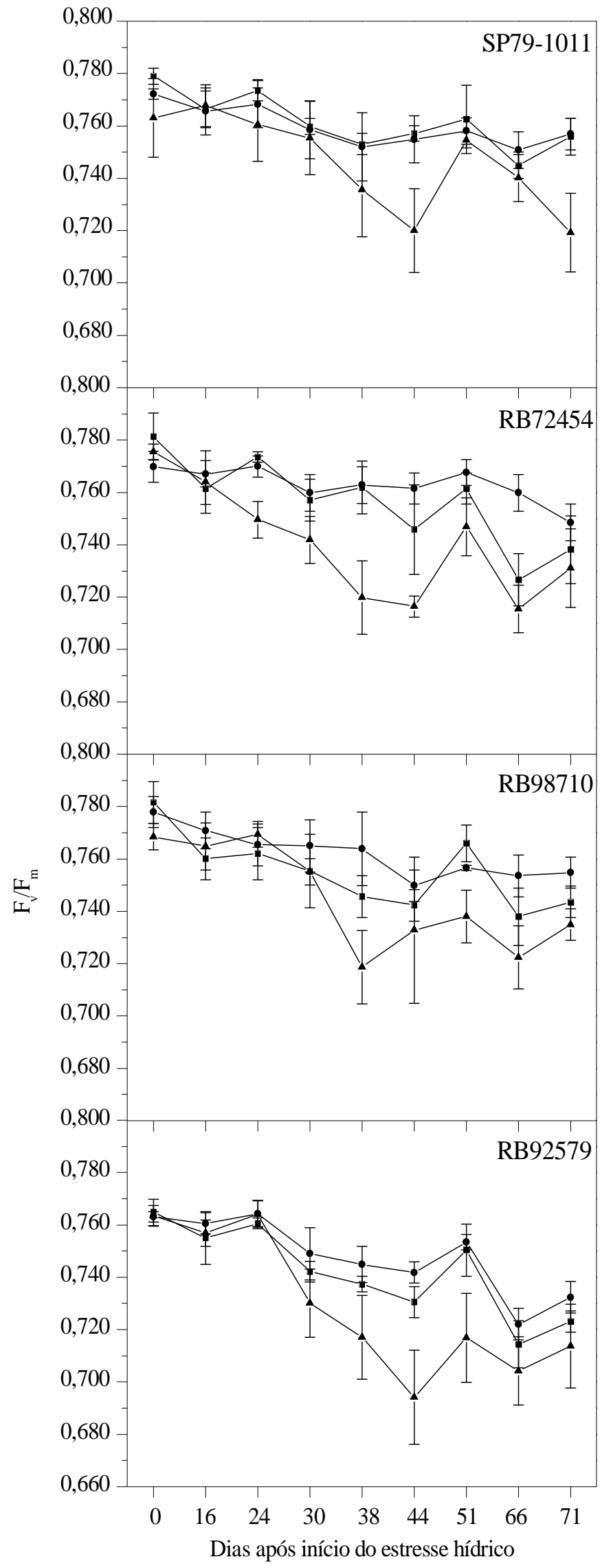

Figura 5. Rendimento quântico da fluorescência da clorofila a $\left(F_{\sqrt{ }} / F_{m}\right)$ em quatro variedades de cana-de-açúcar submetidas aos tratamentos controle $(\rightarrow \bullet-)$, estresse

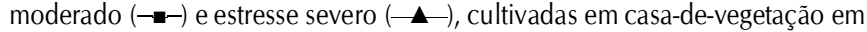
função dos dias de exposição ao estresse hídrico 
Tabela 2. Redução na fluorescência da clorofila a $\left(\mathrm{F}_{v} / \mathrm{F}_{\mathrm{m}}\right)$ entre 0 e 71 dias após a aplicação do estresse em quatro variedades de cana-de-açúcar submetidas aos tratamentos controle (80 a 100\% $A D)$, estresse moderado ( 40 a $60 \%$ AD) e estresse severo $(0 \mathrm{a}$ $20 \%$ AD) cultivadas em casa-de-vegetação

\begin{tabular}{ccc}
\hline Variedades & Tratamentos & $\mathrm{Fv} / \mathrm{Fm}$ \\
& Variedades $\mathbf{x}$ Estresse Hídrico & \\
SP79-1011 & Controle & $1,96 \mathrm{Ab}$ \\
& Estresse moderado & $3,98 \mathrm{Aab}$ \\
& Estresse severo & $6,24 \mathrm{Aa}$ \\
RB72454 & Controle & $1,77 \mathrm{Ab}$ \\
& Estresse moderado & $4,95 \mathrm{Aa}$ \\
& Estresse severo & $5,27 \mathrm{Aa}$ \\
RB98710 & Controle & $2,64 \mathrm{Ab}$ \\
& Estresse moderado & $6,86 \mathrm{Aa}$ \\
& Estresse severo & $5,64 \mathrm{Aa}$ \\
RB92579 & Controle & $3,52 \mathrm{Aa}$ \\
& Estresse moderado & $4,98 \mathrm{Aa}$ \\
& Estresse severo & $5,70 \mathrm{Aa}$ \\
& Tratamentos & \\
& Controle & $2,47 \mathrm{~b}$ \\
& Estresse moderado & $5,19 \mathrm{a}$ \\
& Estresse severo & $5,71 \mathrm{a}$ \\
& $\mathrm{CV}$ (\%) & 37,17 \\
\hline
\end{tabular}

*Redução (\%) entre a primeira (imposição dos tratamentos) e a última leitura, aos 71 dias; **Médias seguidas de letras iguais na mesma coluna, tanto para tratamentos dentro da variedade (letras minúsculas), como para variedades dentro de tratamento (letras maiúsculas), não diferem estatisticamente entre si a nível de $5 \%$ de probabilidade pelo teste de Tukey

transporte de elétrons não foi alterada em função do estresse hídrico.

As reduções observadas neste trabalho são semelhantes àquelas apresentadas por Silva et al. (2007) em quatro genótipos de cana-de-açúcar suscetíveis à seca, os quais observaram reduções significativas acima de $6 \%$, tanto aos 45 como aos 90 dias após o início do déficit hídrico em condições de campo. Em adição, Cruz (2006) encontrou reduções na relação $\mathrm{F}_{\mathrm{v}} / \mathrm{F}_{\mathrm{m}}$ superiores a $60 \%$ em milho entre os tratamentos com teor relativo de água na folha entre 90 e 40\%; esta alteração na atividade fotoquímica pode ser devida à fotoinibição nas plantas submetidas ao estresse hídrico severo, o que leva à formação de oxigênio reativo nos cloroplastos e, consequentemente, a danos físicos no PSII (Maxwell \& Johnson, 2000; Baker \& Rosenqvist, 2004).

Conclui-se, então, que a variedade RB92579 mostrou maior sensibilidade na relação $\mathrm{F}_{\mathrm{v}} / \mathrm{F}_{\mathrm{m}}$ em função do estresse hídrico, haja vista que se observaram os menores valores de $\mathrm{F}_{\mathrm{v}} / \mathrm{F}_{\mathrm{m}}$, indicando danos ao aparato fotossintético atribuindo-se, ainda, este fato, à menor eficiência do fotossistema II em razão de seu reduzido desempenho fotoquímico em relação às demais variedades avaliadas (Silva et al., 2006) porém, sabendo-se que é uma cultura de clico longo e que as avaliações foram realizadas apenas na fase inicial de crescimento vegetativo, recomenda-se um estudo mais detalhado da cultura ao longo de seu ciclo produtivo tendo em vista que a mesma poderia expressar todo o seu potencial genético. Silva et al. (2007) reforçam esta idéia por acreditarem que a partir de 90 dias do início da limitação hídrica seria a melhor época para avaliar o comportamento de variedades de cana-de-açúcar; em adição, Heuer (1997) acredita que as alterações na relação $F_{v} / F_{m}$ geralmente são percebidas quando o estresse é muito severo ou em estresse de média e longa duração.

\section{CONCLUSÕES}

1. O estresse hídrico severo reduz significativamente a condutância estomática, transpiração, fotossíntese líquida e a eficiência no uso da água da produtividade, independente da variedade.

2. As variedades SP79-1011 e RB98710 apresentam maior sensibilidade estomática, reduzindo a condutância estomática e a transpiração, aos 71 DAE, mesmo no tratamento sem estresse hídrico. Por outro lado, a taxa fotossintética é pouco afetada nessas variedades.

3. O estresse hídrico, seja moderado ou severo, provoca pouca redução na eficiência fotoquímica potencial das variedades estudadas.

\section{LITERATURA CITADA}

Arias, M. I. B.; Delgado, E. O.; Carmenate, R. V. Cambios fisiológicos de la caña de azúcar ante el déficit hídrico. 1.ed. México: Universidad Autónoma Chapingo, 1996. 135p.

Baker, N. R.; Rosenqvist, E. Applications of chlorophyll fluorescence can improve crop production strategies: an examination of future possibilities. Journal of Experimental Botany, v.55, n.403, p.1607-1621, 2004.

Beltrão, N. E. de M.; Fideles Filho, J.; Figueirêdo, I. C. de M. Uso adequado de casa-de-vegetação e telados na experimentação agrícola. Revista Brasileira de Engenharia Agrícola e Ambiental, v.6, n.3, p.547-552, 2002.

Bergonci, J. I.; Pereira, P. G. Comportamento do potencial da água na folha e da condutância estomática do milho em função da fração de água disponível no solo. Revista Brasileira de Agrometeorologia, v.10, n.2, p.229-235, 2002.

Bolhàr-Nordenkampf, H. R.; Long, S. P.; Baker, N. R.; Öquist, G.; Schreider, U.; Lechner E. G. Chlorophyll fluorescence as probe of the photosynthetic competence of leaves in the field: A review of current instrument. Functional Ecology, v.3, p.497514, 1989.

Cruz, R. F. D. da. Indução e recuperação do stresse hídrico em variedades portuguesas de milho. Braga: Universidade do Minho, 2006. 182p. Dissertação Mestrado

FAO- Food Production and Security. http://www.fao.org/ag/ AGL/agll/spush/topic1.htm \#brazil. 20 Mar 2008.

Ferreira, P. V. Estatística experimental aplicada à agronomia. 3.ed. Maceió: EDUFAL, 2000. 422p.

Ghannoum, O.; Conroy, J. P.; Driscoll, S. P.; Paul, M. J.; Foyer, C. H.; Lawlor, D. W. Nonstomatal limitations are responsible for drought-induced photosynthetic inhibition in four $\mathrm{C}_{4}$ grasses. New Phytologist, v.159, p.599-608, 2003. 
Glaz, B.; Morris, D. R.; Daroub, S. H. Sugarcane photosynthesis, transpiration, and stomatal conductance due to flooding and water table. Crop Science, v.44, p.1633-1641, 2004.

Heuer, B. Photosynthetic carbon metabolism of crops under salt stress. In: Pessarakli, M. (ed.). Handbook of Photosynthesis. New York: Marcel Dekker, Inc., 1997. p.887-896.

IBGE - Instituto Brasileiro de Geografia e Estatística. http:// www.ibge.gov.br. 25 Mar 2008.

Inman-Bamber, N. G.; Smith, D. M. Water relations in sugarcane and response to water deficits. Field Crops Research, v.92, p.185-202, 2005.

Larcher, W. Ecofisiologia vegetal. São Carlos: RiMa, 2004. 531p.

Lichtenthaler, H. K.; Miehé, J. A. Fluorescence imaging as a diagnostic tool for plant stress. Trends in Plant Science, v.2, p.316-320, 1997.

Maas, E. V.; Hoffman, G. J. Crop salt tolerance - current assessment. Journal of Irrigation and Drainage Division, v.103, p.115-134, 1977.

Maxwell, K.; Johnson, G. N. Chlorophyll fluorescence - a practical guide. Journal of Experimental Botany, v.51, n.345, p.659668, 2000.

Munns, R. Comparative physiology of salt and water stress. Plant, Cell and Environment, v.25, p.239-250, 2002.

Nable, R. O.; Robertson, M. J.; Berthelsen, S. Response of shoot growth and transpiration to soil drying in sugarcane. Plant and Soil, v.207, p.59-65, 1999.
Ribeiro, R. V.; Santos, M. G. dos; Souza, G. M.; Machado, E. C.; Oliveira, R. F. de; Angelocci, L.R.; Pimentel, C. Environmental effects on photosynthetic capacity of bean genotypes. Pesquisa Agropecuária Brasileira, v.39, n.7, p.615623, 2004.

Silva, M. de A.; Jifon, J. L.; Silva, J. A. G. da; Sharma, V. Use of physiological parameters as fast tools to screen for drought tolerance in sugarcane. Brazilian Journal of Plant Physiology, v.19, n.3, p.193-201, 2007.

Silva, M. M. P. da; Vasquez, H. M.; Bressan-Smith, R.; Silva, F. C. da; Erbesdoble, E. D.; Andrade Júnior, P. S. C. de. Eficiência fotoquímica de gramíneas forrageiras tropicais submetidas à deficiência hídrica. Revista Brasileira de Zootecnia, v.35, n.1, p.67-74, 2006.

Smit, M. A.; Singels, A. The response of sugarcane canopy development to water stress. Field Crops Research, v.98, p.91-97, 2006.

Taiz, L.; Zeiger, E. Fisiologia vegetal. 3 ed. Porto Alegre: ARTMED, 2004. 719p.

Tester, M.; Bacic, A. Abiotic stress tolerance in grasses. From model plants to crop plants. Plant Physiology, v.137, p.791793, 2005.

Torres Netto, A.; Campostrini, E.; Oliveira, J. G. de; BressanSmith, R. E. Photosynthetic pigments, nitrogen, chlorophyll $a$ fluorescence and SPAD-502 readings in coffee leaves. Scientia Horticulturae, v.104, p.199-209, 2005. 